\title{
Desenvolvendo a aprendizagem no contexto da ludicidade: definição de papéis e
}

\section{responsabilidades}

\author{
Developing learning in the context of playfulness: defining roles and responsibilities \\ Desarrollar el aprendizaje en el contexto de la alegría: definir roles y responsabilidades
}

Recebido: 24/01/2022 | Revisado: 30/01/2022 | Aceito: 02/02/2022 | Publicado: 04/02/2022

Fabiana Menezes Cunha

ORCID: https://orcid.org/0000- 0003-3645-7371

Universidade Paulista, Brasil

E-mail: fabianamenezescunhacunha@gmail.com

Fabíola Pereira da Silva

ORCID: https://orcid.org/0000-0003-2578-2195 Universidade Paulista, Brasil

E-mail: dasilvafabiola123@gmail.com

Luciana Sales Lima da Costa

ORCID: https://orcid.org/0000-0003-2273-848X Universidade Paulista, Brasil

E-mail: lucianasales832@gmail.com

Maria Carla de Souza Silva

ORCID: https://orcid.org/0000-0001-6258-9111 Universidade Paulista, Brasil

E-mail: professoramariacarlass@gmail.com

Jesimiel Soares dos Santos

ORCID: https://orcid.org/0000-0001-5139-0721 Universidade Paulista, Brasil

E-mail: jesimielgramatic@hotmail.com

José Eduardo Silva

ORCID: https://orcid.org/0000-0002-8483-0305

Universidade Paulista, Brasil

E-mail: silva.j.e@outlook.com

\begin{abstract}
Resumo
Objetivou-se compreender a atuação do lúdico, no desenvolvimento da educação infantil, visando, comprovar sua importância a partir da integração dos envolvidos no processo do ensino-aprendizagem. Buscando como e de quem são as responsabilidades na educação das crianças e como desenvolver esse trabalho de forma agradável e prazerosa. Para a realização desse trabalho utilizou-se a pesquisa bibliográfica. A coleta de dados foi realizada através da plataforma Google Acadêmico para a seleção de artigos, teses, monografias, ebooks e artigos publicados no período de 2017-2021, que estivessem relacionados ao tema proposto trazendo base científica sobre o que é dito por professores e pesquisadores sobre o valor da ludicidade dentro e fora da sala de aula e como os responsáveis por essa aprendizagem podem exercer o seu papel com dedicação, respeito e responsabilidade. Mostrando a importância do desenvolvimento do conhecimento no contexto da ludicidade, focando no desenvolvimento intelectual da criança no ambiente familiar, escolar e sociedade, decorrendo de como ensinar de forma lúdica, possibilitando o conhecimento, criatividade, interação social e o crescimento de uma forma integral, tornando essas crianças seres ativos e transformadores. Essa pesquisa demonstrou que o resultado desse trabalho, traz uma diversidade grande de entendimento acerca do lúdico na vida da criança. A atividades lúdicas junto a tecnologia auxiliam muito no processo de aprendizagem. É brincando que a criança conhece suas limitações, ajudando-a no desenvolvimento cognitivo, psicomotor, social, afetivo e psicológico.
\end{abstract}

Palavras-chave: Lúdico; Aprendizagem; Responsabilidade; Tecnologia.

\begin{abstract}
The objective was to understand the role of play in the development of early childhood education, aiming to prove its importance from the integration of those involved in the teaching-learning process. Seeking how and whose responsibilities are in the education of children and how to develop this work in a pleasant and pleasurable way. To carry out this work, bibliographical research was used. Data collection was carried out through the Google Academic platform for the selection of articles, theses, monographs, ebooks and articles published in the period 2017-2021, which were related to the proposed theme, bringing a scientific basis on what is said by professors and researchers about the value of playfulness inside and outside the classroom and how those responsible for this learning can exercise their role with dedication, respect and responsibility. Showing the importance of developing knowledge in
\end{abstract}


the context of playfulness, focusing on the child's intellectual development in the family, school and society environment, arising from how to teach in a playful way, enabling knowledge, creativity, social interaction and growth in an integral way, making these children active and transforming beings. This research showed that the result of this work, brings a great diversity of understanding about the playful in the child's life. Playful activities with technology help a lot in the learning process. It is by playing that children know their limitations, helping them in cognitive, psychomotor, social, affective and psychological development.

Keywords: Ludic; Learning; Responsibility; Technology.

\section{Resumen}

El objetivo fue comprender el papel del juego en el desarrollo de la educación infantil, buscando demostrar su importancia a partir de la integración de los involucrados en el proceso de enseñanza-aprendizaje. Buscando cómo y de quién son las responsabilidades en la educación de los niños y cómo desarrollar este trabajo de una forma amena y placentera. Para la realización de este trabajo se utilizó la investigación bibliográfica. La recolección de datos se realizó a través de la plataforma Google Academic para la selección de artículos, tesis, monografías, ebooks y artículos publicados en el período 2017-2021, los cuales estuvieron relacionados con la temática propuesta, aportando una base científica sobre lo dicho por los profesores y investigadores sobre el valor de la alegría dentro y fuera del aula y cómo los responsables de este aprendizaje pueden ejercer su rol con dedicación, respeto y responsabilidad. Mostrar la importancia de desarrollar el conocimiento en el contexto de la alegría, enfocándose en el desarrollo intelectual del niño en el entorno familiar, escolar y social, que surge de cómo enseñar de manera lúdica, posibilitando el conocimiento, la creatividad, la interacción social y el crecimiento de manera integral. , haciendo a estos niños seres activos y transformadores. Esta investigación mostró que el resultado de este trabajo, aporta una gran diversidad de comprensión sobre lo lúdico en la vida del niño. Las actividades lúdicas con tecnología ayudan mucho en el proceso de aprendizaje. Es jugando que los niños conocen sus limitaciones, ayudándoles en su desarrollo cognitivo, psicomotor, social, afectivo y psicológico.

Palabras clave: Lúdico; Aprendiendo; Responsabilidad; Tecnología.

\section{Introdução}

Pode-se observar que crianças sofrem influência dos meios em que estão inseridas, acredita-se que o incentivo familiar aliado ao incentivo escolar poderia acarretar em benefícios, mas quais seriam as responsabilidades das pessoas envolvidas nesse processo?

O lúdico é uma metodologia que associa o brincar com responsabilidade de aprender conteúdos (dos Santos et al., 2020), que para muitos podem ser desafiadores, é pertinente atividades que despertem o interesse, há exemplos como jogos e brincadeiras (Silva, 2021). Esse método beneficia principalmente crianças da educação infantil, dado tratar-se de uma prática capaz de gerar interesse e motivação apresentando resultados satisfatórios da perspectiva pedagógica (Rodrigues et al.,).

No contexto da ludicidade, é relevante salientar que a aprendizagem requer muitas estratégias no processo de ensinar e aprender. Atualmente observa-se a necessidade da participação familiar está presente na rotina escolar, assim como é importante o papel do professor com a ludicidade na medida que o mesmo possa oferecer às crianças interação, aprendizagem e outras possibilidades (Moreno, 2018).

Pode-se observar ainda, que a aprendizagem se caracteriza com a mudança de comportamento resultante no treino ou da experiência, é de vital importância que o ambiente escolar consiga beneficiar o desenvolvimento social e cognitivo de qualidade (de Lira Marques, 2019). Sendo assim, trabalhar a ludicidade é investigar como a criança vivencia atividades lúdicas na sala de aula e também no seu contexto familiar, analisando se a criança consegue aprender mais rápido (Rodrigues, Alves \& Sobral, 2019).

Dessa forma a aprendizagem através do lúdico vem contribuindo como uma importante ferramenta aliada ao modelo de ensino tradicional para despertar o engajamento dos estudantes através da utilização de metodologias diversas que estimulem a criatividade, o pensamento crítico e a imaginação dos mesmos de forma natural ao mesclar brincadeiras, jogos e outras formas de diversão como conteúdo visto em classe (Magalhães, 2021). 
Embora seja possível constatar os crescentes avanços no modelo assistencial deste nível de ensino por parte dos professores, os responsáveis precisam se envolver nesse processo visando completar experiências adquiridas na escola e consolidar o aprendizado por parte da criança diante disso (de Souza et al, 2019).

Objetivou-se neste trabalho compreender a atuação do lúdico no desenvolvimento da educação infantil visando comprovar sua importância a partir da integração dos envolvidos no processo da aprendizagem. Sendo, portanto, justificado a relevância da temática uma vez que ao entender a ação da ludicidade na progressão do desenvolvimento das crianças, e compreendendo quais são os facilitadores da aprendizagem infantil através do uso do lúdico, bem como evidenciando como a escola aliada a família pode ser responsável pela aprendizagem das crianças.

Utilizou-se como método a pesquisa do tipo bibliográfica quanto à sua natureza. Dados objetivos se caracterizam por pesquisa quantitativa e descritiva. A coleta de dados se fez pela plataforma Google Acadêmico cujo recorte temporal residiu no período 2017 - 2021 para captura de artigos, e -book documentos e artigos publicados em anais de evento.

\section{Aprendizagem na Educação Infantil: Breve Histórico}

Durante séculos a aprendizagem infantil esteve sob a responsabilidade exclusiva da família, nesse período elas conviviam em casa com os adultos a aprendiam ali suas normas e culturas. Com o surgimento da indústria moderna a estrutura social alterou profundamente os hábitos e costumes das famílias e com isso foi necessário solucionar os problemas das mães que necessitavam trabalhar para acrescentar a renda familiar e não tinham com quem deixar seus filhos, para que fossem cuidados durante sua ausência (Hoscharuck, 2021).

A aprendizagem na educação está ligada a ludicidade, não tem como falar de brincadeira (Oliveira, 2021), e não pensar no infantil, o brincar já nasce com a sociedade e é a partir dele que a criança aprende e começa seus primeiros passos para a vida adulta. É na brincadeira que algumas crianças apresentam falas sem palavras. Assim se entende que a aprendizagem da educação infantil está ligada diretamente a brincadeiras (Silva, 2019).

O Estatuto da Criança e do Adolescente (ECA) diz que: toda criança tem o direito ao brincar (Paulo \& Zatera, 2019). Toda criança tem o direito à aprendizagem, direitos esses que incluem: conviver, brincar, participar, explorar, expressar e conhecer. A música e a afetividade têm um papel importante na aprendizagem, a afetividade é um elemento primordial que está presente nas relações humanas (do Nascimento et al., 2017), e em todas as fases da vida da criança, é uma linguagem que está presente em diversas situações cotidianas da vida e possui diferentes funções, serve para: acalmar relaxar, dançar e comunicar-se (Brasil, 2017).

A educação infantil (EI), é a primeira etapa da educação básica oferecida em creches e pré-escolas às quais se caracterizam como espaços institucionais não domésticos que constituem estabelecimentos educacionais públicos ou privados que cuidam de crianças de 0 a 5 anos de idade em período diurno com jornada integral ou parcial (Lima, 2021).

O educar e a aprendizagem devem estar assegurados a todo momento através de atividades lúdicas, visto que a fase da EI é um período escolar muito importante para a socialização das crianças, com a construção da sua identidade e do seu desenvolvimento. A Base Nacional Comum Curricular (BNCC) expõe seis eixos fundamentais para a aprendizagem, sendo eles: Conviver, Brincar, Participar, Explorar, Expressar e conhecer-se (Brasil, 2017). Para a EI as escolas devem fornecer às crianças meios de responderem às suas indagações e curiosidades para que as mesmas possam ampliar seus conhecimentos e utilizem no seu cotidiano (Ferraz \& Sasseron, 2017).

A EI é um dos períodos mais complexos para o desenvolvimento humano, principalmente quando se refere ao desenvolvimento emocional, intelectual, social e motor e as escolas que trabalham com essa modalidade de ensino necessita proporcionar um ambiente seguro, educativo e afetivo, onde os educadores possam conduzir o aluno a fazerem novas descobertas para a construção do conhecimento. O educando passa por um processo de adaptação, ao sair do ambiente familiar. 
Ele começa sua segunda socialização e tem novas experiências, por isso é fundamental que o aluno se sinta bem acolhido e amado por seu educador, pois o relacionamento afetivo é importante demais para o emocional e o lado cognitivo (Souza \& Arruda, 2019), contemplando a disciplina (Souza, 2017).

Nas histórias contadas, às crianças se divertem, usando a imaginação, porém, é necessário também que possam ser diferenciados o bem do mal, o certo do errado, sendo importante nessa etapa onde as crianças estão construindo a sua visão de mundo. Portanto, a aprendizagem infantil está ligada ao processo da ludicidade na comunicação social e afetiva.

A criança na aprendizagem passa por etapas onde consegue alcançar sua capacidade e a mesma é estudada pela psicologia do desenvolvimento infantil, buscando entender o desenvolvimento: afetivo, cognitivo, emocional e social, nesse desenvolvimento a interação torna- se importante pois por meio dela ela vai se tornando independente (Camargo et al., 2019).

A aprendizagem é um processo associado ao desenvolvimento pessoal, onde são adquiridos ou modificados comportamentos, habilidades, conhecimentos e valores. Através de experiências, observações e raciocínios, diversos estudos demonstram relevância na parceria família e escola é fundamental para esse processo, pois tudo se inicia com a família para ser complementado pela escola que é um ambiente rico, em estímulos e exemplos fundamentais para o processo de aprendizagem na trajetória escolar (Folquitto, 2018).

\subsection{A Responsabilidade do Desenvolvimento da Aprendizagem}

O termo lúdico deriva da palavra latina "ludus" cujo significado é brincar. Esse conceito compreende o brincar como uma manifestação livre e espontânea, onde a diversão e o entretenimento atuam como fontes facilitadoras de conhecimentos.

Dessa forma, a abordagem lúdica na EI vem contribuindo como uma importante ferramenta capaz de despertar o engajamento dos estudantes através da utilização de metodologias diversas que estimulam a criatividade, o pensamento crítico e a imaginação dos mesmos de forma natural ao mesclar brincadeiras, jogos e outras formas de diversão com o conteúdo visto em classe, assim como, colaborando para o desenvolvimento linguístico, cognitivo, social, motor e afetivo das crianças (Santos \& Pereira, 2019).

A metodologia representa um recurso importante para a educação infantil por possuir como estratégia a abordagem de conteúdos de forma dinâmica e criativa, se aliando assim a metodologia tradicional, que para muitos estaria engessada e obsoleta e, atuando como facilitadora do processo de aprendizagem da criança (Silva, 2021).

A aprendizagem na EI necessita de uma boa interação família e escola, fazendo com que as famílias entendam que a entrada dessas crianças nessa modalidade de ensino vai muito além do brincar, traz para as crianças a sua segunda socialização, além de proporcionar habilidades para o seu cotidiano, dando mais autonomia e conhecimento paras próximas etapas da educação (Santos \& Pereira, 2019).

Confere-se que o papel da escola é formar cidadãos, bem como, prepará-los para o mercado de trabalho, diz-se que a responsabilidade do professor é proporcionar um material mais variado possível, é apresentar situações interessantes dando o justo valor a sua interpretação, criando conflitos superáveis, estimulando o raciocínio, estas são algumas propostas que ajudarão as crianças a avançar rumo a construção do conhecimento temático (Fuhr, 2020).

O lúdico é uma metodologia praticada e divertida conhecida em muitas escolas trazendo diversas definições como brincadeiras de qualidade ou brincar com responsabilidade, o não brincar por brincar, mas brincar para aprender e aprender brincando. Em busca de muitas explicações para o lúdico se entende que a criança que aprende com o lúdico, consegue explicar o que aprendeu sem medo, mostrando que realmente entendeu. o lúdico funciona sim, é um auxílio em sala de aula por existir muitos docentes diversificando cada um com suas dificuldades na aprendizagem.

A responsabilidade do professor é praticar o lúdico em sala de aula, elaborando de forma compreensiva (da Silva et al., 2021). Cabe ao professor a responsabilidade, saber apresentar o lúdico em sala de aula, construindo forma facilitadoras de 
compreensão, o papel do professor nesta aprendizagem é indispensável, suas atitudes, concepções e intervenções serão fatores determinantes para seus alunos do infantil. Pois cabe ao mesmo o estímulo do trabalho com o lúdico, sabendo que o método nasceu para ajuda no entendimento das disciplinas, como suporte facilitador para dificuldades que existiam (de Lemos \& Santos, 2021).

O professor não deve deixar de lado o desenvolvimento da habilidade social, nesse processo lúdico, pois deve ter uma relação humanizada, para que aconteça uma aprendizagem significativa, para que essa aprendizagem não seja apenas uma diversão, o mediador deve levar para a criança uma leitura mais consciente acerca da prática do brincar. E, consequentemente, um aluno bem preparado na EI, reflete no ensino fundamental (de Medeiros, 2017).

A responsabilidade de ensinar os filhos também é da família, a escola complementa esse na parte pedagógica, de acordo com o artigo 22 do Estatuto da Criança e do Adolescente (ECA). Porém, os pais e responsáveis da criança muitas vezes chegam na escola, deixam seus filhos, e exigem que os professores os eduquem, como se não bastasse as muitas atividades atribuídas aos docentes (Alves, 2020).

Desde que surgiu a escola democrata, todas as crianças têm o direito e o dever de frequentar a instituição de ensino, mesmo sem querer e por vezes, contra sua própria vontade muitos alunos comparecem a escola por obrigação, a falta de entendimento traz o desinteresse nas aulas. Fato que reside em uma das dificuldades da educação escolar, com a queda no rendimento o primeiro a sofrer é o próprio aluno, os conflitos entre os docentes passam a ser constantes, sendo assim aprendizagem vai ficando cada vez mais comprometida.

Desta forma a criança não consegue prestar atenção nas aulas, começa a faltar e com essa situação as notas tendem a cair. É na convivência familiar que a criança estabelece seu primeiro contato com a sociedade, recebendo ajuda e apoio, sendo fundamental a participação direta constante e consciente dos pais e responsáveis na educação das crianças (Costa \& Souza, 2019. Portanto, no ceio familiar ocorrem o acompanhamento do desenvolvimento e desempenho escolar, com intervenção pertinente ao processo de educacional. Dado que a escola é a instância que se soma ao ambiente familiar.

A parceria tem relação proposta pedagógica, considerando que os pais conheçam e participem do processo de construção. Dado que a participação familiar é parte indissociável na condução do aprendizado, onde os responsáveis participem efetivamente dos movimentos escolares. Pois os pais que participam da educação dos filhos têm resultados satisfatórios no final do ano letivo (dos Santos Oliveira et al., 2017).

Em algumas escolas ainda não há ações que aproximem as famílias do ambiente escolar. A maioria dos pais sabem do seu papel e de sua responsabilidade, mas tem dificuldades em assumir junto a escola, por não saber como fazer. Os pais até entendem suas responsabilidades quanto ao futuro de seus filhos, mas se sentem incapazes, tendo certo desconforto, foge de suas responsabilidades.

São por essas causas que existem as leis para dividir as tarefas na educação, as responsabilidades de educar começa dentro do seio familiar, posto que a família é a primeira instituição apresentada à criança, a mesma deve estar salva de toda forma de negligência, de acordo com o artigo 33 da Lei de Diretrizes e Bases da Educação Nacional (LDB) (Saviani, 2019).

Este cenário enseja a condição da escola em assumir o processo de educar, abdicando seu papel norteador para os caminhos de uma formação cidadã consciente. Instituindo condições para a escolha da profissão na busca por uma sociedade mais justo e igualitária. Infere-se a importância de primar pela participação da família em todo o processo educativo das crianças, pois não há escola e professores excelentes capazes de suprir a ausência familiar. Dado que a responsabilidade da educação é conjunta (Silva \& Kaulfuss, 2020).

Quando se fala em ludicidade, lembra alegria, brincadeira entre os professores e os pais com os alunos/filhos, que desenvolvem várias capacidades, como a linguagem, a motora, e cognitiva, e a efetivas. Portanto, as brincadeiras em família são muito importantes no processo de desenvolvimento e aprendizagem. Além do ato de brincar também colaborar para 
interação social entre as crianças e os adultos, portanto não pode estar fora do cotidiano, e não pode apenas está inserido no meio escolar. Esse relacionamento no cotidiano infantil é extremamente importante (Silva et al., 2017).

O Professor não deve deixar de lado o desenvolvimento da habilidade social, nesse processo lúdico, pois deve ter uma relação humanizada, em que aconteça uma aprendizagem significativa, e que não seja apenas uma diversão, o mediador deve levar para a criança uma leitura mais consciente acerca da prática do brincar. Observando que um aluno bem preparado na educação infantil, reflete no ensino fundamental (de Medeiros, 2017).

A responsabilidade de educar os filhos é da família, a escola complementa essa educação, de acordo com o artigo 22 do ECA. Porém, os pais, as mães ou os responsáveis pela criança muitas vezes chegam na escola, jogam seus filhos, e exigem que os professores eduquem, como se não bastasse as muitas atividades atribuídas aos docentes (Paulo \& Zatera, 2019).

Muitos alunos comparecem a escola por obrigação, a falta de interesse nas aulas é uma das principais dificuldades da educação escolar, com a falta de comprometimento o primeiro a sofrer é o próprio aluno, os conflitos entre os docentes passam a ser constante, sendo assim aprendizagem vai ficando cada vez mais comprometida.

A criança não consegue prestar atenção nas aulas, começa a faltar e com essa situação as notas tendem a cair. É na convivência familiar que a criança estabelece seu primeiro contato com a sociedade, recebendo limites e regras sendo fundamental a participação direta, constante e consciente dos responsáveis com a educação escolar (Costa \& Souza, 2019). Uma aprendizagem significativa resulta da participação ativa de pais e professores, a interação supera os momentos comemorativos escolar, ou seja, transpõem-se aos muros da escola. Dado que engendram-se resultados positivos ao fim do ano letivo (Paulino, 2020).

A responsabilização do processo educacional das crianças tem início no ceio familiar, uma vez que constitui o princípio dos contatos da criança com o mundo. Desta forma, a responsabilidade da família reside no começo da formação do indivíduo juntamente com a escola na conjectura de informação, e neste contexto a escola e a família formam a base do processo de aprendizagem de maneira complementar estabelecida nesta relação (Silva \& Kaulfuss, 2020).

A família deve preparar-se para receber as crianças, sempre se preocupando em ajudar os mesmos, com atividades lúdicas estruturadas e impulsionadoras. O lar é um espaço preparado para a vivência da criança, sendo de fundamental importância apertar os laços familiares para o desenvolvimento dela, a qual se conectam ao outro de uma forma divertida.

Quando se fala em ludicidade, lembra alegria, brincadeira entre os professores e os pais com os alunos/filhos, que desenvolvem várias capacidades, como a linguagem, a motora, e cognitiva, e a efetivas. Portanto, as brincadeiras em família são muito importantes no processo de desenvolvimento e aprendizagem. Além do ato de brincar também colaborar para interação social entre as crianças e os adultos, portanto não pode estar fora do cotidiano, e não pode apenas está inserido no meio escolar. Esse relacionamento no cotidiano infantil é extremamente importante (Silva et al., 2017).

Por isso o dever dos pais, é guiar, incentivar nas brincadeiras, sendo um animador, possibilitando momentos de grande interação familiar, pensando na saúde e qualidade de vida dos (as) filhos (as), incentivando a prática de atividades físicas, posto que o brincar vai além da diversão.

A brincadeira é vista como uma atividade para o fim de dia elétrico, entretanto o lúdico vai muito além de tal objetivo. Com as brincadeiras pode fazer ciência, trabalhando com a imaginação, produzindo experiências cotidianas, ao perceber a realidade, concordar as informações repassadas, problematizar, tornando-se criador e construtor de novos conhecimentos.

É importante promover experiências, nas quais as crianças possam falar, e ouvir, potencializando sua participação na cultura oral, pois é na escuta de história na participação em conversas, na descrição, nas narrativas elaboradas individualmente, ou em grupo, e nas implicações com as múltiplas linguagens que as crianças que constituem ativamente como sujeito singular, que pertence a um grupo social (Fonseca et al., 2021). 


\subsection{Da Teoria à Prática: o Lúdico na Perspectiva do Professor e do Aluno}

Na teoria o lúdico se mostra muito fácil, mas a falta de conhecimento desta metodologia tem afastado muitos alunos do ensino infantil de sua sala de aula, o professor que não sabe explicar o que é o lúdico, também não sabe transmitir o mesmo (Nascimento, 2020).

O lúdico é uma prática divertida e conhecida em muitas escolas trazendo diversas definições como brincadeiras de qualidade ou brincar com responsabilidade não brincar por brincar, mas brincar para aprender e aprender brincando, em busca de muita explicação para o lúdico se entende que a criança que aprende com o lúdico consegue explicar com mais força o que entendeu sem medo.

Demonstrando que realmente entendeu o que foi pedido para fazer nas atividade, em busca de provar que o lúdico é um auxílio em sala de aula por existir muitos docentes diversificado cada um com suas dificuldades na aprendizagem, o condutor da sala muitas vezes dá a explicação dos conteúdos de forma aplicada em livros ou no caderno em busca de uma a melhor compreensão vem o lúdico podendo ser transmitido através dos jogos ou brincadeiras assim traz o melhor entendimento de forma divertida facilitando uma maior entusiasmo e deixando para trás o medo e o sentimento de inferioridade (de Oliveira \& de Souza, 2020).

Se sabe que o papel da escola é formar cidadãos e prepará-lo para o futuro o mercado de trabalho, se diz que a responsabilidade do professor é proporcionar um material mais variado possível, é apresentar situações interessantes dando o justo valor a sua interpretação, criando conflitos superáveis, estimulando o raciocínio, estas são algumas propostas que ajudarão as crianças a avançar rumo a construção do conhecimento temático (Novakowski \& Saraiva, 2019).

Embora as atividades lúdicas tenham se estabelecido no meio acadêmico como um recurso benéfico e de baixo custo sendo cada vez mais disseminado na prática escolar, um dos desafios desta prática está relacionado a falta de conhecimento sobre esta metodologia na visão de alguns pais e cuidadores que compreendem o lúdico da perspectiva limitante onde o ato de brincar se estabelece sem qualquer objetivo pedagógico, podendo desta forma contribuir para o desencorajamento e consequente evasão infantil na participação das atividades propostas pelo professor (Moraes et al., 2021).

Recentemente acerca do apego por parte de alguns pais e responsáveis ao modelo tradicional de ensino, onde o ato de brincar era encarado apenas da perspectiva do divertimento durante o recreio, onde as crianças brincavam livremente, contribuindo assim para persistência da crença de que este modelo seria superior aos outros por proporcionar uma maior ênfase nas atividades pedagógicas exercidas dentro de sala.

No entanto, se levarmos em consideração que os pilares educacionais da criança serão desenvolvidos durante os seus primeiros anos de vida através das suas experiências e interações com o ambiente no qual está inserida, conseguiremos compreender a razão pela qual a aprendizagem através do lúdico vem contribuindo como uma importante ferramenta aliada ao modelo tradicional para despertar o engajamento dos estudantes uma vez que através da utilização de metodologias diversas, a criança tem a oportunidade de vivenciar o mundo e exercitar de maneira prática os conteúdos abordados em sala de aula através do estímulo a sua criatividade, pensamento crítico e imaginação (de Lira Marques, 2019).

O modelo tradicional de ensino consiste na elaboração de aulas expositivas, onde o docente transmite o conhecimento para o discente através de um modelo de repetição do conteúdo e cópias, de uma forma engessada onde a garantia do aprendizado se estabelece na medida em que o aluno se mostra capaz de reproduzir os discursos da mesma maneira que lhe foi ensinado.

Embora este método de ensino ainda seja o mais encontrado em nosso país, é preciso repensar sua aplicação prática uma vez que se trata de um modelo que prioriza a quantidade de assuntos transmitidos ao aluno ao invés da qualidade da informação. Os recursos aliados ao modelo são majoritariamente os livros e o quadro branco, dispositivos estes que se mostram incapazes de despertar o interesse dos alunos (Pereira \& Alves, 2020). 
Para o professor da educação infantil, a metodologia lúdica se apresenta como uma forte aliada uma vez que os jogos e brincadeiras, já existiam nas escolas durante os momentos destinados ao horário do recreio o que contribui para uma melhor aceitação por parte dos alunos durante a implementação da metodologia lúdica uma vez que algumas atividades já conhecidas previamente poderão apenas ser repensadas para transmitir uma mensagem educacional garantindo um melhor aproveitamento e desempenho a respeito da temática desenvolvida dentro de sala de aula (Moraes et al., 2021).

Sendo reconhecido como um recurso capaz de contribuir para a aprendizagem e desenvolvimento da criança de maneira leve e prazerosa, a metodologia lúdica foi incluída na BNCC, como uma atividade que deve ser realizada em sala de aula e demais espaços. Aprovada para o ensino infantil e fundamental, compreende o brincar como prática essencial no processo educativo das crianças, permitindo que seja possível a criação de um espaço na qual a mesma possa se desenvolver da perspectiva pedagógica, social e pessoal a partir das experiências vivenciadas.

Este documento norteia a conduta do profissional da educação infantil, considerando a criança como capaz de constituir sua identidade e subjetividade através da sua relação com o meio e com os outros ao vivenciar experiências em um ambiente cultural, acolhedor e instigante. Nessa perspectiva o documento se aprofunda na estruturação dos direitos e objetivos de aprendizagem da criança, compreendendo-os em campos de experiência, que são constituídos através de um arranjo curricular cuja base teórica envolve o acolhimento das situações e experiências vivenciadas pelas crianças através da metodologia lúdica e a sua capacidade de aplicar os conhecimentos adquiridos de forma transdisciplinar. Nesse contexto, a BNCC define cinco campos de possibilidades no qual o professor poderá atuar (Brasil, 2017).

A organização dos campos de experiência no arranjo curricular, surge como uma estratégia para garantir de forma efetiva que os direitos das crianças sejam respeitados, ao passo que oferece um suporte para os professores realizarem as atividades lúdicas demonstrando que existe uma base teórica que sustenta a execução do seu trabalho.

No entanto, embora seja uma metodologia cujos benefícios são comprovados no meio científico, o lúdico ainda se apresenta como uma estratégia desafiadora para os profissionais que já se encontravam adaptados ao modelo tradicional e que agora se deparam com a necessidade de ajustar sua prática de ensino ao novo método.

Este fato se justifica uma vez que alguns desses docentes não foram ensinados sobre esta metodologia durante suas formações tão pouco tiveram acesso a capacitações que pudessem facilitar o processo de incorporação desta prática ao seu dia a dia, dificultando assim a formação integral do aluno a partir de um método que valoriza seu potencial cognitivo exercitando de forma crítica e criativa a capacidade de reconstrução de conceitos e habilidades indo de encontro assim aos objetivos atuais da educação (da Silva Almeida \& da Silva Santos, 2018).

Portanto, compreende-se como responsabilidade do professor, buscar constantemente capacitações que os amparem dentro da metodologia lúdica, fornecendo estratégias capazes de prepará-lo para fornecer aos seus alunos autonomia através do método (Ramos et al., 2020).

A compreensão acerca desta modalidade de ensino, permite ao docente um melhor diálogo com a coordenação pedagógica contribuindo assim para um maior apoio por parte da mesma com relação a sua prática em sala de aula assim como garante uma melhor comunicação com os pais e responsáveis das crianças, ao esclarecer que a metodologia lúdica se baseia em teorias científicas e desmistificando a crença de que a prática se trata apenas do brincar por brincar, colaborando assim para a diminuição da evasão escolar na educação infantil.

Mediante o exposto, compreendemos que na metodologia lúdica a participação e interesse do aluno são fatores importantes para garantir a qualidade do aprendizado, sendo esta sua responsabilidade, uma vez que este método se baseia na aquisição de novos conhecimentos e habilidades a partir de experiências adquiridas previamente (Ramos; Guimarães \& Mota, 2020). 


\subsection{Ludicidade e as Novas Tecnologias na Educação}

A infância é um período da vida onde se adquire vários conhecimentos. O corpo e a mente estão em constante transformação, tanto nos aspectos físicos, psicológicos, emocionais, sociais e cognitivos. Daí a importância de um estímulo adequado para cada fase e fatores acima mencionados (Lopes et al., 2021).

Vive-se na sociedade da informação, que com o surgimento da tecnologia permitiu comunicação a longa distância, interferindo no cotidiano, escolar, familiar e social. Provocando mudanças na sociedade, nas relações interpessoais e principalmente na área da educação (Carls, 2017).

A palavra tecnologia nos leva ao desenvolvimento, avanço e conveniência. Ao longo da história confirma-se sinais de uma tecnologia elementar, necessária para a execução de atividades primordiais à sobrevivência humana. Com o passar do tempo e o advento da globalização as tecnologias foram avançando de maneira muito rápida, envolvendo a vida das pessoas, modificando, dessa maneira o homem e sua cultura (Araújo, 2019).

Segundo Araújo (2019). ao conjunto de conhecimentos e princípios científicos que se aplicam ao planejamento, a construção e à utilização de um equipamento em um determinado tipo de atividade chamamos de "tecnologia". Para construir qualquer equipamento uma caneta esferográfica ou um computador. Os homens precisam pesquisar, planejar e criar o produto ou serviço, o processo. Ao conjunto de tudo isso, chamamos de tecnologias.

Quanto ao aspecto cognitivo é de suma importância tanto no ambiente familiar, quanto no escolar que seja trabalhado de maneira a alcançar os objetivos da aprendizagem. Nesse contexto entra o lúdico que tem por objetivo facilitar de maneira prazerosa o aprendizado, visto que o mesmo acontece através de brincadeiras, jogos, entre outras atividades.

Esse processo contribui para o desenvolvimento das relações entre crianças e docentes / docentes e crianças (Magalhães, 2021). Com o advento das tecnologias da informação e comunicação, surge um grande desafio por parte da escola e educadores no que concerne a utilização das mesmas, nas brincadeiras, jogos que visam o desenvolvimento infantil e ao mesmo tempo em cuidar para que essas ferramentas não interfiram de forma nociva na aprendizagem das crianças (Marques \& Santin, 2021; da Rosa \& Ferreira, 2018).

Atualmente as crianças estão cada vez mais conectadas no mundo digital, tanto através de smartphones, tablets, notebooks, entre outros. Esse posicionamento traz diversos benefícios, se utilizados de forma adequada. Porém se não utilizadas com monitoramento e direcionamento adequados, podem interferir de modo a prejudicar o aprendizado, as relações pessoais das mesmas (Marques \& Santin, 2021).

Entre as dez competências gerais apresentadas pela BNCC, dois itens trazem a tecnologia como habilidade para o aprendizado. Enquanto uma diz respeito ao uso das linguagens tecnológicas e digitais, a outra fala em utilizar a tecnologia de maneira significativa, reflexiva e ética (Brasil, 2018).

A inclusão dessas competências, na verdade, é um reflexo do atual cenário tecnológico do mundo em que vivemos. As crianças, chamadas de nativos digitais, já nascem e crescem com as tecnologias presentes em seu dia a dia. O virtual é algo comum, dessa forma, as escolas precisavam se adaptar a essas mudanças (Farias et al., 2020).

Segundo a BNCC a quarta competência ressalta para que os alunos se comuniquem bem. É preciso entender, analisar e criticar os variados tipos de linguagens e plataformas, incluindo a digital, para que assim, eles possam se expressar e partilhar informações. A competência relembra também a importância de uma experiência mais completa através de diferentes formatos de expressão, a fim de tornar os alunos capazes de ouvir outras pessoas com atenção, interesse e respeito por suas ideias e sentimentos (Brasil, 2018).

A quinta competência da BNCC foca no uso com senso crítico. Ela reconhece o papel fundamental da tecnologia, mas é preciso ter um acompanhamento e responsabilidade de uso. Além disso, o estudante deve dominar o universo digital, sendo capaz de usar ferramentas multimídia para aprender e produzir (Brasil, 2018). Portanto, a ideia desses textos é introduzir a 
tecnologia que está tão presente no dia a dia das crianças em um contexto de aprendizagem formal, tanto para aprender a utilizar os meios digitais quanto para lidar com os novos hábitos e relações decorrentes do seu uso. A tecnologia quando bem implantada na escola traz diversos benefícios para a educação.

Entretanto, as escolas precisam executar atividades que permitam o contato das crianças com a tecnologia para a construção de significados e conhecimentos, utilizando-se de jogos e brincadeiras digitais que complementam os campos de experiência dirigidos pela BNCC. Para isso, os professores precisam se planejar e aprender a usar as tecnologias nas salas para todas as faixas etárias (Farias et al., 2020).

O conhecimento prévio sobre as novas tecnologias abre um leque de oportunidades facilitando a transmissão dos saberes de professor para alunos que podem ser desenvolvidos em várias áreas de ensino. Pouco provável é que o professor seja substituído pelas tecnologias, porém aqueles que não tiverem flexibilidade de adaptação às mesmas tornar-se-ão ultrapassados frente aos que estão preparados, disposto a integrar as tecnologias como aliadas no processo de aprendizagem dos discentes.

Tal profissional deverá ser um elo entre os alunos e os recursos tecnológicos disponíveis de modo a extrair o máximo de seus benefícios para a intenção da aprendizagem da criança no caso da educação infantil (Carls, 2017). De acordo com Farias et al. (2020), há pontos positivos e negativos da tecnologia que exigem discussões. Nem todas as crianças têm acesso ao uso da tecnologia, são vários os fatores que levam a esse contexto, dentre os quais: a desigualdade social, localidade em que residem, e a condição econômica. Outro ponto negativo é o contato muito cedo que as crianças têm com essas ferramentas influenciando no comportamento social e nos seus desenvolvimentos afetivo e cognitivo.

Além de interferir nos hábitos tradicionais que envolvem o contato físico com as pessoas e o meio ambiente. A dependência a esses dispositivos eletrônicos pode causar sintomas de ansiedade, intolerância, depressão, entre outros. Um dos pontos positivos é que as crianças que são acompanhadas por um adulto e fazem uso moderado das tecnologias, são mais comunicativas e concentradas (Queiroz, 2019).

No Brasil, as tecnologias na Educação se originaram com o objetivo de contribuir com o trabalho dos docentes, objetivando favorecer as atividades de ensino e aprendizagem. Dessa forma o docente necessita adaptar, programar, usar meios que ajudem para uma melhor qualidade de ensino (Marques \& Santin, 2021).

\section{Metodologia}

Utilizou-se como metodologia a revisão bibliográfica (Carvalho et al., 2019), que se enquadra como revisão sistemática. Utilizando a abordagem qualitativa, descritiva e exploratória (Pereira et al., 2018). Dado que a coleta de dados buscou artigos científicos, documentos, e-book e trabalhos de conclusão de curso, durante o período de setembro a novembro de 2021, cujos materiais foram recuperados de plataformas online, tendo como base de dados principal a plataforma do Google Acadêmico.

Inicialmente foram encontradas 119 obras, onde selecionamos 28 artigos, 11 trabalhos de conclusão, 02 documentos e 02 ebooks. Os artigos selecionados preencheram os seguintes critérios: ter sido realizado no Brasil e terem sido publicados em língua portuguesa entre o período de 2017 e 2021. Compreendendo os eixos temáticos Ludicidade, Tecnologia na educação, Responsabilidade e aprendizado e Relação professor-aluno. A análise dos dados seguiu com base em argumentos qualitativos considerando o temário descrito. Considerando a seleção randômica e sistemática das publicações, onde utilizou-se do recurso on line por meio do site WordArt.com ou nuvem de palavras.

\section{Resultados e Discussões}


Conforme visto no estudo, através da leitura dos artigos anteriormente citados, o desenvolvimento da aprendizagem no contexto da ludicidade para as crianças do ensino infantil estará intrinsecamente ligada à vivência de experiências que permitam a criação de um raciocínio crítico aliado à criatividade e motivação. A Figura 1 constitui o conjunto de palavraschave com base no temário supradito, culminando na seleção dos artigos para compor a base teórica do estudo, no período de 2017 a 2021. E na Tabela 1 tem-se os principais artigos que subsidiaram a análise e discussão.

Figura 1. Nuvem de palavras originadas a partir dos eixos temáticos selecionados e depositados na plataforma Google Acadêmico no período de 2017 a 2021.

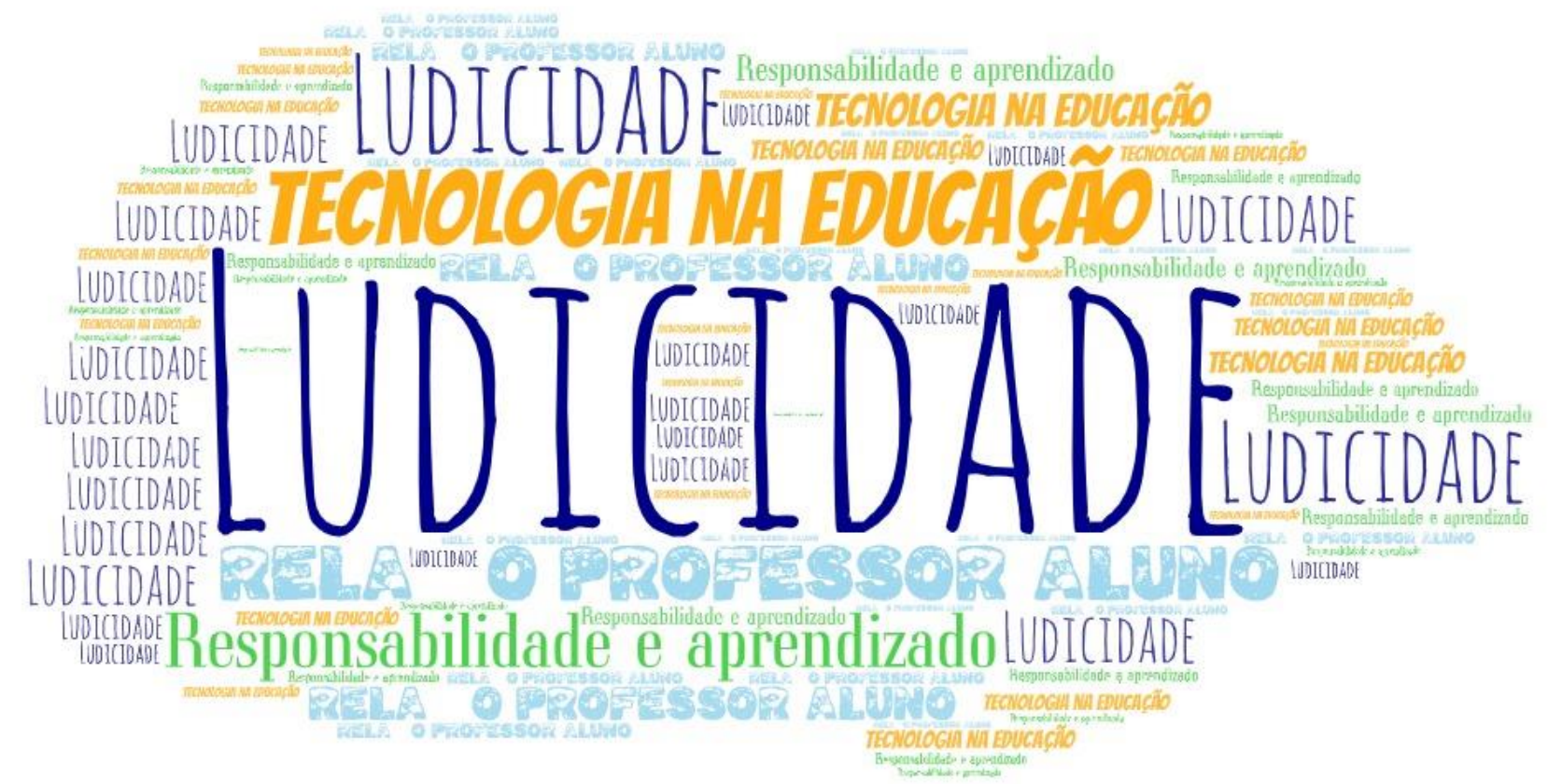

Fonte: Site WordArt.com (2021). 
Tabela 1. Artigos selecionados por relevância ao temário em estudo.

\begin{tabular}{|c|c|c|c|}
\hline AUTOR & ANO & TÍTULO & PERIÓDICO \\
\hline Da Rosa \& Ferreira & 2018 & $\begin{array}{l}\text { A rede do movimento pela base e sua influência na base nacional } \\
\text { comum curricular brasileira }\end{array}$ & $\begin{array}{l}\text { Teoria e Prática da } \\
\text { Educação }\end{array}$ \\
\hline $\begin{array}{l}\text { Da Silva Almeida \& } \\
\text { Da Silva Santos }\end{array}$ & 2018 & $\begin{array}{l}\text { Lúdico na formação de professores: contribuições da brinquedoteca na } \\
\text { capacitação docente. }\end{array}$ & $\begin{array}{llr}\text { Revista } & \text { Práticas } & \text { de } \\
\text { Linguagem } & & \\
\end{array}$ \\
\hline Da Silva et al & 2021 & O lúdico de acordo com a BNCC & $\begin{array}{l}\text { Research, Society and } \\
\text { Development }\end{array}$ \\
\hline De Lemos \& Santos & 2021 & $\begin{array}{l}\text { Matemática lúdica na Educação Infantil: contribuições do trabalho } \\
\text { psicopedagógico lúdico para a prevenção e superação de dificuldades } \\
\text { relacionadas ao pensamento matemático }\end{array}$ & Caderno Intersaberes, \\
\hline De Lira Marques & 2019 & $\begin{array}{l}\text { Contribuições das atividades lúdicas para o ensino e aprendizagem na } \\
\text { educação infantil }\end{array}$ & Revista Caparaó \\
\hline De Souza et al & 2019 & $\begin{array}{l}\text { O incentivo do professor para a participação da família na vida escolar } \\
\text { dos discentes }\end{array}$ & $\begin{array}{l}\text { Brazilian Journal } \\
\text { Development }\end{array}$ \\
\hline $\begin{array}{l}\text { Do Nascimento, De } \\
\text { Oliveira \& De Fátima }\end{array}$ & 2017 & Afetividade na educação infantil & Revista Saberes Docentes \\
\hline $\begin{array}{l}\text { Dos Santos Oliveira, } \\
\text { Braga \& Prado }\end{array}$ & 2017 & $\begin{array}{l}\text { Participação da família no desenvolvimento da aprendizagem da } \\
\text { criança }\end{array}$ & Estação Científica \\
\hline $\begin{array}{l}\text { Dos Santos, De } \\
\text { Oliveira Santos \& De } \\
\text { Brito Araújo }\end{array}$ & 2020 & $\begin{array}{l}\text { Lúdico como ferramenta da psicopedagogia no desenvolvimento } \\
\text { integral das crianças }\end{array}$ & $\begin{array}{l}\text { Revista Científica do } \\
\text { Instituto Federal de Alagoas }\end{array}$ \\
\hline
\end{tabular}

Fonte: Autores (2021).

Dessa forma, a estratégia lúdica se apresenta como uma importante ferramenta capaz de contribuir com a consolidação desse aprendizado ao despertar a motivação e interesse das crianças através da utilização de jogos e brincadeiras relacionados com as temáticas desenvolvidas dentro de sala de aula.

A observação crítica da prática da metodologia lúdica evidencia que o envolvimento dos pais e responsáveis aliados a equipe escolar proporcionará melhores resultados no que diz respeito a aprendizagem desses alunos, o que nos faz perceber, portanto, que em consonância com o que foi encontrado na literatura acadêmica, é uma responsabilidade de todos criar um ambiente acolhedor capaz de incentivar o desenvolvimento das habilidades e potencialidades infantis.

Aos pais e responsáveis recai, portanto, o compromisso de estar ciente da proposta pedagógica da escola, compreendendo as características da metodologia lúdica visando proporcionar um acompanhamento diário da evolução do raciocínio lógico desenvolvido pela criança, uma vez que de acordo com as legislações vigentes é a família a responsável pela formação do indivíduo.

Compreende-se, portanto, como responsabilidade do professor da educação infantil o fornecimento de informações acerca da metodologia lúdica aos pais e responsáveis, a utilização de estratégias que facilitem o processo de incorporação e compreensão da metodologia lúdica por parte dos alunos, além da busca constante por capacitações que o mantenham atualizado.

De acordo com o exposto, é responsabilidade do aluno se manter interessado e participante ativo nas atividades lúdicas oferecidas visando garantir a qualidade do seu aprendizado através da aquisição de novos conhecimentos e habilidades.

Evidenciou-se neste estudo que é possível utilizar as novas tecnologias como recursos aliados da metodologia lúdica ao incorporá-los como uma estratégia capaz de gerar interesse e motivação nos alunos da educação infantil além de proporcionar uma maior integração no diálogo entre pais e professores.

\section{Considerações Finais}

Diante dos estudos realizados defendemos que a ludicidade abre um espaço para que as crianças possam expressar seus sentimentos, e a sua criatividade, ao mesmo tempo em que ela tem a oportunidade de desenvolver a aprendizagem e 
adquirir novos conhecimentos. Percebemos que o lúdico é de extrema importância para o desenvolvimento pessoal, cognitivo, orgânico, emocional, psicossocial e cultural.

É necessário discorrer que qualquer atividade lúdica, seja por meio de brincadeiras, jogos, faz de conta, contação de história e musicalização, produz estímulos, originando o pleno desenvolvimento das crianças. Cabe aos professores de educação infantil modificar o brincar em trabalhos pedagógicos para que as crianças encontrem motivação na aprendizagem.

Por fim, cabe registrar que o estudo demonstra-se relevante, dado que elenca discussões envolvendo pesquisas na área de educação ressaltando a importância da responsabilidade no desenvolvimento da aprendizagem da criança. Sendo assim, sugere-se futuras pesquisas fundamentando e despertando o interesse de futuros profissionais da educação.

\section{Agradecimentos}

A Universidade Paulista - UNIP, Recife/Pernambuco; à Coordenação de Aperfeiçoamento de Pessoal de Nível Superior - CAPES.

\section{Referências}

Alves, M. G. D. S. (2020). Vivências lúdicas na educação infantil e o contexto de pandemia de Covid-19 no Brasil (2020). Trabalho de Conclusão de Curso. (Pedagogia à distância) - Universidade Federal da Paraíba PB. https://repositorio.ufpb.br/jspui/handle/123456789/17887.

Araújo, L. M. D. C. (2019). A relação família e escola na educação infantil: reflexões sobre a percepção de pais e educadoras no município de Várzea-PB. Trabalho de Conclusão de Curso. (Pedagogia à distância) - Universidade Federal da Paraíba. PB. 2019. https://repositorio.ufpb.br/jspui/handle/123456789/17978.

Brasil. (2017). Base Nacional Comum Curricular. Brasília, DF, 2017. http://basenacionalcomum.mec.gov.br/.

Brasil. (2018). Base Nacional Comum $\quad$ Curricular. Brasília, http://basenacionalcomum.mec.gov.br/images/BNCC_EI_EF_110518_versaofinal_site.pdf.

Camargo, C. A. C. M., Camargo, M. A. F., \& de Oliveira Souza, V. (2019). A importância da motivação no processo ensino-aprendizagem. Revista Thema, 16(3), 598-606. https://doi.org/10.15536/thema.V16.2019.598-606.1284.

Carls, R. I. (2017). A ludicidade e o uso das tecnologias da informação e comunicação na educação infantil: desafio contemporâneo. Trabalho de Conclusão de Curso. (Especialização em mídias na educação) - Universidade Federal de Santa Maria. Três Passos. RS. 2017. http://repositorio.ufsm.br/handle/1/12273.

Carvalho, L. O. R., Duarte, F. R., Menezes, A. H. N., Souza, T. E. S. et al. (2019). Metodologia Científica: teoria e aplicação na educação a distância. 83 p.: $20 \mathrm{~cm}$. Livro digital.

Costa, E. L., \& Souza, J. R. S. (2019). Família e escola: as contribuições da participação dos responsáveis na educação infantil. Khóra: Revista Transdisciplinar, 6(7). http://site.feuc.br/khora/index.php/vol/article/viewFile/166/113.

da Rosa, L. O., \& Ferreira, V. S. (2018). A rede do movimento pela base e sua influência na base nacional comum curricular brasileira. Teoria e Prática da Educação, 21(2), 115-130. https://doi.org/10.4025/tpe.v21i2.45391.

da Silva Almeida, L., \& da Silva Santos, J. B. (2018). Lúdico na formação de professores: contribuições da brinquedoteca na capacitação docente. Revista Práticas de Linguagem, 492-501. https://doi.org/10.34019/2236-7268.2018.v8.28393.

da Silva, AV, da Silva, CM, Marques, JB, \& de Farias Silva, W. (2021). Educação Infantil: O lúdico de acordo com a BNCC. Pesquisa, Sociedade e Desenvolvimento, 10 (12), e479101220599-e479101220599. https://doi.org/10.33448/rsd-v10i12.20599.

de Lemos, K. L. T., \& Santos, M. C. (2021). Matemática lúdica na Educação Infantil: contribuições do trabalho psicopedagógico lúdico para a prevenção e superação de dificuldades relacionadas ao pensamento matemático. Caderno Intersaberes, 10(27), 95-107. file:///C:/Users/silva/Downloads/1997Texto\%20do\%20artigo-5372-1-10-20210820.pdf.

de Lira Marques, J. V. (2019). Contribuições das atividades lúdicas para o ensino e aprendizagem na educação infantil. Revista Caparaó, 1(2), e10-e10. https://revistacaparao.org/caparao/article/view/10/14.

de Medeiros, M. F. (2017). O papel da afetividade na relação professor e aluno e sua implicações na aprendizagem. Revista on line de Política e Gestão Educacional, 1165-1178. https://doi.org/10.22633/rpge.v21.n.esp2.2017.10179.

de Oliveira, D., \& de Souza, H. M. (2020). O lúdico no processo compreensão de número e quantidade na educação infantil. Revista do Seminário de Educação de Cruz Alta-RS, 7(01), 414-415. http://www.exatasnaweb.com.br/revista/index.php/anais/article/view/837.

de Souza, M. J. A., de Albuquerque, R. N., da Silva, R. M., da Silva, S. R., \& da Silva, M. D. L. S. (2019). O incentivo do professor para a participação da família na vida escolar dos discentes. Brazilian Journal of Development, 5(12), 29296-29303. https://doi.org/10.34117/bjdv5n12-087 
do Nascimento, V. H., de Oliveira, M. A. M., \& de Fátima, O. M. (2017). Afetividade na educação infantil. Revista Saberes Docentes, 2(3). http://revista.ajes.edu.br/index.php/rsd/article/view/79/57.

dos Santos Oliveira, I. L., Braga, A. P., \& Prado, C. M. N. (2017). Participação da família no desenvolvimento da aprendizagem da criança. Estação Científica (UNIFAP), 7(2), 33-44. http://dx.doi.org/10.18468/estcien.2017v7n2.p33-44.

dos Santos, A. C., de Oliveira Santos, J., \& de Brito Araujo, M. J. (2020). Lúdico como ferramenta da psicopedagogia no desenvolvimento integral das crianças. Educte: Revista Científica do Instituto Federal de Alagoas, 10(1), 1175-1183. https://periodicos.ifal.edu.br/educte/article/view/1648/1228

Farias, F. C., Dal Pizzol, A., \& Santinello, J. (2020). A tecnologia digital e a relação com o brincar infantil: reflexões teóricas. Revista Sítio Novo, 4(4), 271281. http://dx.doi.org/10.47236/2594-7036.2020.v4.i4.271-281p

Ferraz, A. T., \& Sasseron, L. H. (2017). Espaço interativo de argumentação colaborativa: condições criadas pelo professor para promover argumentação em aulas investigativas. Ensaio Pesquisa em Educação em Ciências (Belo Horizonte), 19. https://doi.org/10.1590/1983-21172017190117.

Folquitto, C. T. (2018). Teorias de ensino-aprendizagem na educação infantil. Senac. $9788539621613 . \quad$ p. 268. https://books.google.com.br/books?id=4mV2DwAAQBAJ\&dq=Teorias+de+ensino-aprendizagem+na+educa\%C3\%A7\%C3\%A3o+infantil\&lr=\&hl=ptBR\&source=gbs_navlinks_s.

Fonseca, P. D., da Silva, M. P., \& Leite, P. S. (2021). A influência do lúdico no desenvolvimento infantil. Revista Amor Mundi, 2(6), 39-45. https://doi.org/10.46550/amormundi.v2i6.123

Fuhr, I. L. (2020). O professor e sua responsabilidade na sociedade contemporânea. Fractal: Revista de Psicologia, 32, 199-203. https://doi.org/10.22409/1984-0292/v32_i-esp/38852.

Hoscharuck, J. (2021). Expectativas de famílias de crianças da pré-escola em relação ao trabalho pedagógico na educação infantil. Trabalho de Conclusão de Curso (Programa de Pós-Graduação Profissional em Educação) - Universidade Federal da Fronteira do Sul. Campus Erechim. https://rd.uffs.edu.br/handle/prefix/4640.

Lima, I. A. (2021). Contribuições da Literatura para o desenvolvimento do trabalho pedagógico na Educação Infantil em consonância com a BNCC. Trabalho de Conclusão de Curso (Licenciatura em Pedagogia) - Universidade do Estado da Bahia. http://hdl.handle.net/20.500.11896/1783

Lopes, A. P., Laranjeiras, A. L. C., Neves, R. W. S., \& Alencar, V. V. (2021). O uso excessivo das tecnologias digitais e seus impactos nas relações psicossociais em diferentes fases do desenvolvimento humano. Caderno de Graduação-Ciências Biológicas e da Saúde-UNIT-ALAGOAS, 6(3), 166-166. https://periodicos.set.edu.br/fitsbiosaude/article/view/8964.

Magalhães, I. A. D. (2021). Lúdico e tecnologia nos processos de ensino-aprendizagem da educação infantil. 40 f. Trabalho de Conclusão de Curso (Licenciatura em Pedagogia) - Universidade de Brasília, Brasília. https://bdm.unb.br/handle/10483/28702

Marques, L. S., \& Santin, M. (2021). Práticas Lúdicas e o Advento da Tecnologia: As Possibilidades e os Desafios do Trabalho Docente na Educação Infantil. Revista Pleiade, 15(32), 74-83. https://doi.org/10.32915/pleiade.v15i32.677.

Moraes, G. S. C., Coelho, H. G., \& de Azevedo, G. X. (2021). A importância do lúdico na Educação Infantil. REEDUC-Revista de Estudos em Educação (2675-4681), 7(2), 96-125. https://www.praxia.ueg.br/index.php/reeduc/article/view/11569/8305.

Moreno, G. L. (2018). A relação escola-família e a organização do trabalho pedagógico na educação infantil. Revista Ibero-Americana de Estudos em Educação, 13(3), 1187-1203. https://doi.org/10.21723/riaee.v13.n3.2018.9778.

Nascimento, L. F. D. A. (2020). A importância da ludicidade no desenvolvimento infantil. Trabalho de Conclusão de Curso (Pedagogia à distância) Universidade Federal da Paraíba PB. 2020 https://repositorio.ufpb.br/jspui/handle/123456789/19156.

Novakowski, L., \& Saraiva, K. (2019). Educação infantil, governamento da infância e produção de capital humano. Momento-Diálogos em Educação, 28(2), 143-161. https://doi.org/10.14295/momento.v28i2.8107.

Oliveira, M. B. D. (2021). A brincadeira e a ludicidade como recursos de aprendizagem. Trabalho de Conclusão de Curso. (Pedagogia à distância) Universidade Federal da Paraíba PB. 2021. https://repositório.ufpb.br/jspui/handle/123456789/20545

Paulino, J. C. L. (2020). A relação entre pais e escola: a influência da família no desempenho escolar do aluno. Trabalho de Conclusão de Curso. (Pedagogia à distância) - Universidade Federal da Paraíba PB. 2020. https://repositorio.ufpb.br/jspui/handle/123456789/17844.

Paulo, F. A. A., \& Zatera, L. C. S. (2019). Brinquedos, brincadeiras e os jogos na educação infantil. Caderno Intersaberes, 8(15). file://C:/Users/silva/Downloads/1259-Texto\%20do\%20artigo-2814-1-10-20191111.pdf.

Pereira, D. O., \& Alves, G. S. (2020). Educação profissional: do paradigma fragmentado a uma pedagogia da integração. Revista Brasileira da Educação Profissional e Tecnológica, 2(19), 10117. https://doi.org/10.15628/rbept.2020.10117.

Pereira, A. S. et al. Metodologia da pesquisa científica. UFSM. https://repositorio.ufsm.br/bitstream/handle/1/15824/Lic_Computacao_Metodologia-PesquisaCientifica. pdf, 2018.

Queiroz, J. L. D. D. (2019). O brincar e as tecnologias digitais na educação infantil. Trabalho de Conclusão de Curso. (Licenciatura em Pedagogia) - Unidade Delmiro Gouveia-Campus do Sertão, Universidade Federal de Alagoas, Delmiro Gouveia. http://www.repositorio.ufal.br/jspui/handle/riufal/5319.

Ramos, J. R., Guimarães, J. N., \& Mota, B. G. N. (2020). Educação infantil e o desenvolvimento da autonomia. Revista Educação \& Ensino, 4(2). http://periodicos.uniateneu.edu.br/index.php/revista-educacao-e-ensino/article/view/69/58. 
Research, Society and Development, v. 11, n. 2, e52411226078, 2022

(CC BY 4.0) | ISSN 2525-3409 | DOI: http://dx.doi.org/10.33448/rsd-v11i2.26078

Rodrigues, E. N., Alves, M. D. S. J., \& Sobral, M. D. S. C. (2019). O Brincar e o Aprender na Educação Infantil. ID on line Revista de Psicologia, 13(43), 187-196. https://doi.org/10.14295/idonline.v13i43.1520.

Santos, A. A., \& Pereira, O. J. (2019). A importância dos jogos e brincadeiras lúdicas na Educação Infantil. Revista Eletrônica Pesquiseduca, 11(25), 480-493. https://periodicos.unisantos.br/pesquiseduca/article/view/899/pdf.

Saviani, D. (2019). A lei da educação: LDB: trajetória, limites e perspectivas. Autores associados. E-book. ISBN - 857496431X, 9788574964317. P. 368. https://books.google.com.br/books?id=gMqxDwAAQBAJ\&dq=A+lei+da+educa\%C3\%A7\%C3\%A3o:+LDB:+trajet\%C3\%B3ria,+limites+e+perspectivas\&lr $=\&$ hl $=$ pt - BR\&source $=$ gbs_navlinks_s.

Silva, A. D. S. D., Valenciano, P. J., \& Fujisawa, D. S. (2017). Atividade Lúdica na Fisioterapia em Pediatria: Revisão de Literatura. Revista Brasileira de educação Especial, 23, 623-636. https://doi.org/10.1590/S1413-65382317000400011.

Silva, C. R., \& KaulfusS, M. A. (2020). A importância da família na educação infantil. Revista científica eletrônica de ciências aplicas da FAIT. http://www.fait.revista.inf.br/imagens_arquivos/arquivos_destaque/NWgq2JCop9F9YwD_2017-1-21-11-14-37.pdf.

Silva, L. P. D. (2021). Aprender brincando: o lúdico na educação infantil. Trabalho de Conclusão de Curso. (Pedagogia à distância) - Universidade Federal da Paraíba PB. 2021. https://repositorio.ufpb.br/jspui/handle/123456789/20502

Silva, M. (2019). O Envolvimento do Pai na Educação pré-escolar dos Filhos. Dissertation. (Mestrado em Educação) - Instituto Superior de Educação e Ciências, Lisboa. 2019. http://hdl.handle.net/10400.26/31285.

Souza, C., \& Arruda, M. (2019). Afetividade na educação infantil. Revista Inclusiones, 581-595. http://revistainclusiones.org/pdf33/42\%20vol\%206\%20num\%204\%20pernambucomundo2019octubdiciemb19incl.pdf.

Souza, F. P. D. (2017). A importância da disciplina de artes na educação: capacidade e criatividade das crianças. Monografia (Graduação em Educação do Campo - Licenciatura) - Universidade de Brasília, Planaltina, DF. 2017. https://bdm.unb.br/bitstream/10483/19586/1/2017_FernandaPatriciadeSouza.pdf. 2021 